\title{
\}
}

\author{
М.М. Тлиш, О.А. Катханова, Т.Г. Кузнецова, Ж.Ю. Наатыж
}

ГБОУ ВПО «Кубанский государственный медицинский университет» Минздрава России 350063, Краснодар, ул. Седина, д. 4

Цель. Оценить клиническую эсффективность монотерапии средствами гаммы Исеак в лечении акне легкой степени тяжести.

Материал и методы. Под наблюдением находились 28 пациентов с акне легкой степени тяжести, которые получали в виде монотерапии средства гаммы Исеак. Динамику кожного процесса оценивали визуально (шкала общей тяжести угрей OTV S. Liden) и с помощью инструментальных методов — себуметрии (аппарат Callegari SOFT 5,5).

Результаты. Высокая эфффективность проведенной терапии зарегистрирована у $39 \%$ больных, значительное улучшение - у $53 \%$, улучшение - у $8 \%$, отсутствие эффректа — у $0 \%$.

Заключение. Продемонстрирована высокая клиническая эфффективность, хорошая переносимость, отсутствие побочных эффректов, что позволяет рекомендовать гамму Исеак для монотерапии и комбинированного лечения акне легкой степени тяжести.

Ключевые слова: акне, легкая степень тяжести, гамма Исеак, высокая клиническая эффективность, хорошая переносимость.

Контактная информация: 255-04-44. Вестник дерматологии и венерологии 2013; (2): 79—83.

\section{Innovations in the external therapy of acne}

\author{
M.M. Tlish, 0.A. Katkhanova, T.G. Kuznetsova, Zh.Yu. Naatyzh
}

Kuban State Medical University

Sedina str., bldg 4, 350063, Krasnodar, Russia

Goal. To assess the clinical efficacy of a monotherapy with the use of products belonging to the Hyseac line for the treatment of light acne.

Materials and methods. The study involved 28 patients with light acne, who were administered products belonging to the Hyseac line as a monotherapy. The dynamics of the skin processes was assessed visually (S. Liden's acne general severity scale) and with the use of instrumental methods — sebometry (Callegari SOFT 5.5).

Results. High efficacy of the administered therapy was registered in $39 \%$ of the subjects, substantial improvement was recorded in $53 \%$ of the subjects, improvement — in $8 \%$ of the subjects while no effect was registered in $0 \%$ of the subjects. Conclusion. The drug demonstrated high clinical efficacy, good tolerance and absence of any adverse effects, which makes it possible to recommend products belonging to the Hyseac line as a monotherapy and concomitant treatment of light acne.

Key words: light acne, Hyseac line, high clinical efficacy, good tolerance. 
Акне - одно из распространенных заболеваний, которым страдают около 90-95\% населения земного шара [1]. В Российской Федерации этот дерматоз встречается у 88\% обследованного населения в возрасте от 16 до 25 лет [2]. Заболевание поражает около $80 \%$ подростков женского пола и 90 - мужского пола во всех этнических группах [3]. Дебютирует заболевание у девочек в возрасте от 12 до 14 лет, у мальчиков - в 14-15 лет [4, 5].

Согласно современным представлениям клинические проявления при угревой болезни развиваются в результате взаимодействия четырех патогенетических механизмов:

андрогенной гиперстимуляции функции сальных желез, сопровождающейся увеличением продукции и изменением состава кожного сала;

фолликулярного гиперкератоза;

- роста и размножения Propionibacterium acne;

воспаления.

Определена этиологическая роль Propionibacterium acne не только в процессе комедоногенеза, но и в развитии воспалительных фрорм акне. В последние годы в литературе появляются сообщения о том, что гликопептиды $P$. аспе являются лигандами и активируют трансмембранные рецепторы TLR2 и TLR4, а воспалительная реакция при акне сопровождается увеличением экспрессии IL-6 и IL-8 на кератиноцитах, выстилающих фолликулы, макрофрагах дермы, повышением синтеза бета-дефензина, кателецидина [6].

Наличие высыпаний на открытых участках кожного покрова приводит к развитию психоэмоциональных переживаний, депрессий, дисморфофообий, социальной дезадаптации, развитию комплекса неполноценности у $30-50 \%$ пациентов и впервые манифестирует еще в юношеском возрасте [7-11]. Степень выраженности нозогенных реакций при данном заболевании зачастую не соответствует тяжести кожного процесса. Все это диктует необходимость поиска новых методов терапии и базового ухода у пациентов с акне.

Лечение акне проводится в соответствии с тяжестью течения дерматоза, учетом эффективности терапии и включает, согласно международным рекомендациям, системную и наружную терапию. Выделяют легкую, среднюю и тяжелую степень тяжести акне. При легкой степени тяжести заболевания назначают только наружную терапию, в качестве которой широко используются препараты, содержащие топические ретиноиды, бензоилпероксид, антибиотики, азелаиновую кислоту и др.

Важным аспектом терапии акне является индивидуальный подбор средств ухода за кожей и их сочетание. В связи с этим специалистами из дерматологической лаборатории Урьяж была разработана целая гамма средств Исеак по уходу за жирной и комбинированной кожей.
Цель исследования: оценить клиническую эффективность монотерапии средствами гаммы Исеак в лечении акне легкой степени тяжести.

\section{Материал и методы}

На кафедре дерматовенерологии ГБОУ ВПО «Кубанский государственный университет» Минздрава России под наблюдением находилось 28 пациентов (12 мужчин и 16 женщин) в возрасте от 12 до 25 лет (средний возраст $18 \pm 2$ года) с акне легкой степени тяжести. Давность процесса варьировала от 2 мес. до 6 лет. У 21\% больных кожный патологический процесс носил ограниченный характер (поражение лица), у 79\% - распространенный (с вовлечением кожи верхней трети туловища).

Критерии включения больных в исследование:

возраст больных от 12 до 25 лет;

- наличие акне легкой степени тяжести (менее 10 папулопустулезных элементов);

- письменное согласие пациентов.

Критерии исключения больных из исследования:

детский возраст до 12 лет;

- среднетяжелые и тяжелые фрормы акне;

паличие хронических заболеваний внутренних органов в стадии декомпенсации;

- использование гормональных препаратов в течение последних 3 мес.;

口 осложненный аллергологический анамнез;

п пихические заболевания.

Динамику кожного процесса оценивали визуально (шкала общей тяжести угрей ОTУ Liden S.) и с помощью себуметрии (аппарат Callegari SOFT 5,5) спустя 2 нед., 1 и 3 мес. от начала лечения.

Критерием эфффективности проводимой терапии являлось изменение показателя ОТУ: высокая эффективность - уменьшение показателя ОТУ более чем на $80 \%$, значительное улучшение - регресс на $50-70 \%$; улучшение - регресс элементов на 50-30\%; без эфрфректа (менее 25\%) - отсутствие динамики кожного процесса к окончанию курса терапии. Также учитывали переносимость, выраженность субъективных ощущений и комплаентность пациентов.

Все больные предъявляли жалобы на высыпания, жирность кожи. Клиническая картина характеризовалась умеренным или выраженным салообразованием, воспалительной реакцией, открытыми и закрытыми комедонами, папулопустулезными элементами в количестве менее 10, что соответствовало легкой степени тяжести акне. Средний индекс ОТУ составил 32,4 (рис. 1,a).

Программа ухода за кожей включала: очищение, тонизацию, противовоспалительные и кераторегулирующие средства, адекватное увлажнение и маскировку дефектов кожи разрешенными средствами.

На первом этапе для гигиены кожи назначался «мягкий очищающий гель» 2 раза в день утром 


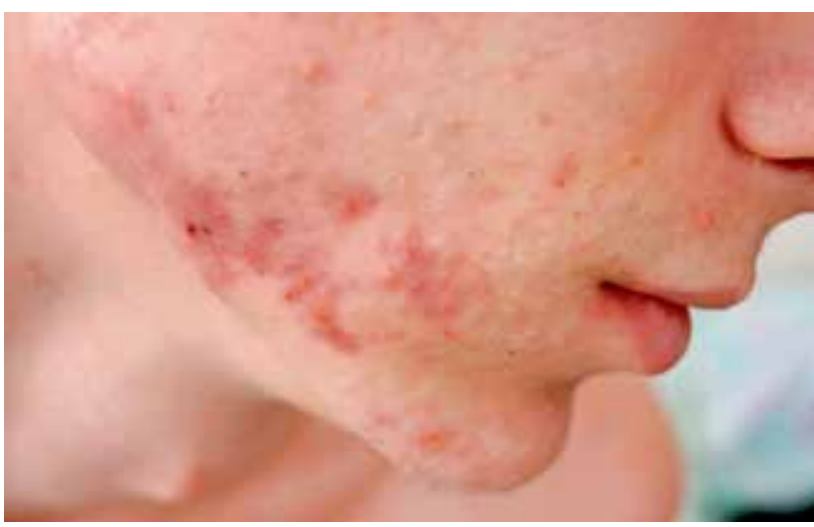

a

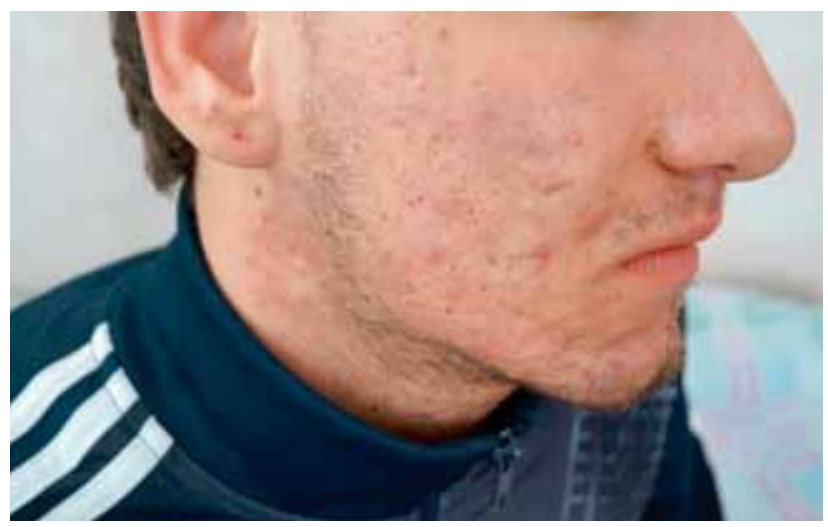

$\sigma$

Рис. 1. Состояние кожи лица пациента С. 22 лет до начала терапии (а) и через 2 нед. от начала терапии (б)

и вечером. Гель Исеак на основе термальной воды Урьяж, в состав которого входит экстракт кипрея, пироктон оламин, обеспечивает глубокое очищение и восстанавливает баланс микрофлоры кожного покрова, подготавливает ее к дальнейшему уходу. Следует отметить, что 25\% пациентов, имеющих более выраженную секрецию кожного сала, дополнительно применяли гидроматирующую эмульсию, которая сохраняет матирующий эффект в течение 12 ч и является прекрасной основой для макияжа. При выраженной комедональной форме 2 раза в неделю использовали мягкую отшелушивающую маску-гоммаж, содержащую каолин, альфагидроксикислоты, микросферы. Такой состав способствовал мягкому и деликатному воздействию на процессы кератинизации, сглаживал кожный рельеф и выравнивал тон кожи. Далее на очищенную кожу лица равномерно утром и вечером наносили средства базовой терапии - Al-эмульсию. Средство специально разработано для решения специфических проблем жирной или комбинированной кожи, склонной к воспалению. Запатентованный TLR2-Regul комплекс позволяет воздействовать на воспалительные эле- менты и профилактировать их развитие, осуществлять патогенетически обоснованную терапию акне. В качестве восстанавливающего увлажняющего средства лицам, получавшим ранее системную и топическую терапию ретиноидами, рекомендовали Исеак успокаивающий уход. Пациентам, ведущим активный образ жизни, у которых не исключалась возможность инсоляции, для профилактики рецидивов обязательным является использование средств дерматокосметики с высоким индексом защиты от УФ-А и УФ-Б-лучей. Солнцезащитная эмульсия Исеак (SPF 30, 50), содержащая комплекс фрильтров нового поколения с Тиносорбом М, себосомы кипрея, витамин E, абсолютно безопасна, некомедоногенна и обеспечивает полноценную гидратацию и антиоксидантную защиту.

\section{Результаты и обсуждение}

Динамика показателей клинической картины представлена в таблице. Через 2 нед. от начала терапии были отмечены первые положительные результаты терапии: резко сократилось (на 28\%) количество воспалительных элементов по сравнению

\begin{tabular}{lcccc}
\hline Показатели визуального осмотра & До лечения & Спустя 2 нед. & Спустя 1 мес. & Спустя 3 мес. \\
\hline Открытые комедоны & $89 \pm 5,7$ & $60 \pm 6,1$ & $41,4 \pm 5,4$ & $18 \pm 3,7$ \\
\hline Закрытые комедоны & $46 \pm 4,3$ & $32 \pm 2,8$ & $21,6 \pm 2,6$ & $8,7 \pm 3,2$ \\
\hline Папулы & $7 \pm 2,4$ & $5,2 \pm 1,4$ & $12,5 \pm 1,2$ & $3,6 \pm 1,8$ \\
\hline Пустулы & $8 \pm 2$ & $2.4 \pm 1,1$ & $5,3 \pm 0,8$ & $0,56 \pm 0,2$ \\
\hline
\end{tabular}




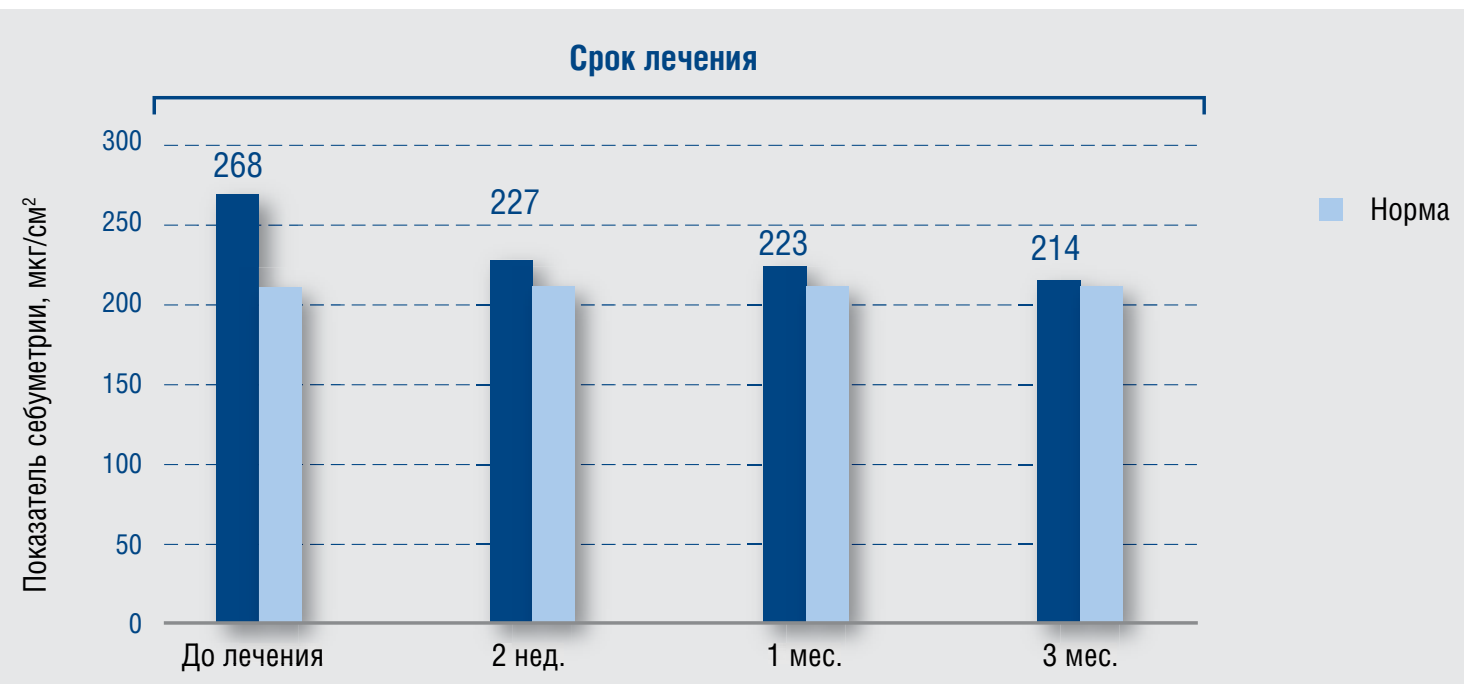

Рис. 2. Динамика показателя себуметрии в процессе терапии

с исходным уровнем, уменьшились эритема, сало- и комедонообразование. В течение последующего месяца терапевтический эффрект продолжал нарастать, клинически выражаясь в улучшении «качества кожи» - снижении сального блеска, улучшении ее текстуры и цвета (рис. 1, б). Наиболее активно регрессировали островоспалительные элементы, в первую очередь пустулы, их количество уменьшилось на 34\%. На рис. 2 представлена характеристика показателя себуметрии, который за время лечения приблизился к нормальным значениям. Спустя 3 мес. высокая эфрективность терапии зарегистрирована у $39 \%$ больных (индекс ОТУ 9,6 $\pm 1,5$ ), значительное улучшение - у 53\%, улучшение - $8 \%$, отсутствие эфрректа - 0\%. Показатели эффрективности и качества лечения, по оценке пациентов, представлены на рис. 3 и 4. Положительная оценка, данная большинством участников исследования, соответствует представленным выше данным регресса клинической симптоматики. Лишь у незначительной части респондентов возникли трудности с последовательностью применения средств и необходимостью соблюдать режим их использования. Высокие потребительские свойства гаммы: легкость нанесения, хорошая впитываемость, комфрортность использования, отсутствие нежелательных эффектов - послужили стимулом к дальнейшему применению препаратов в качестве ухода за кожей.

Проведенное исследование продемонстрировало высокую клиническую эффрективность, хорошую переносимость, отсутствие побочных эфрфектов, что позволяет рекомендовать гамму Исеак для монотерапии и комбинированного лечения акне легкой степени тяжести.

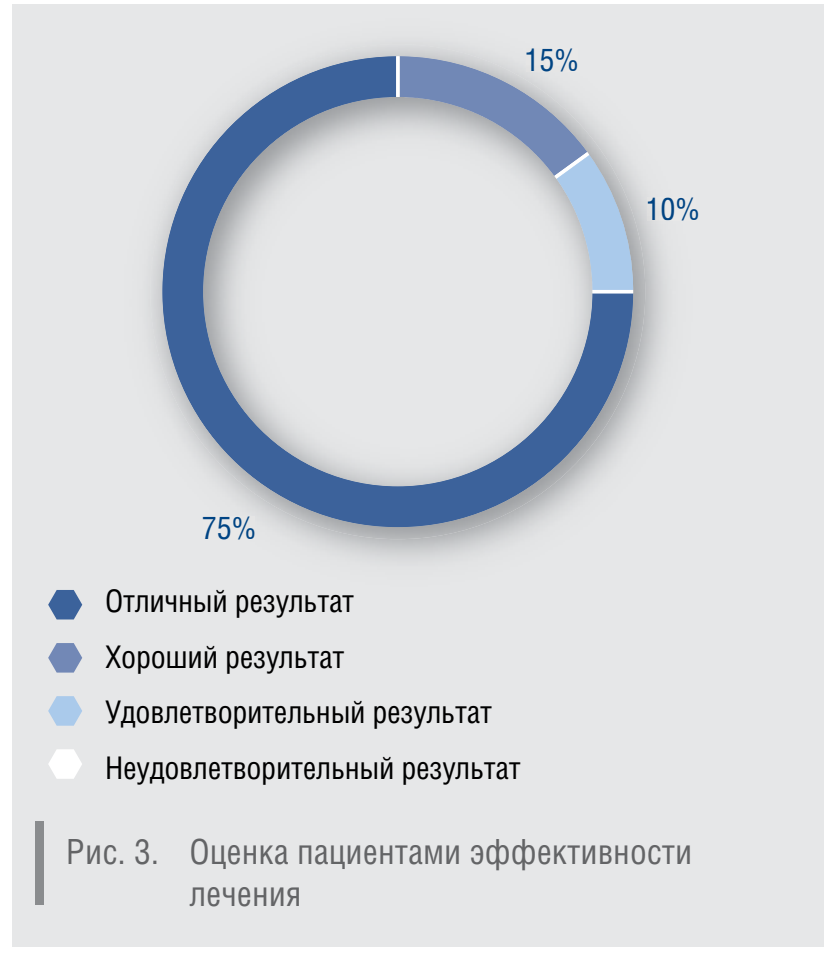

Появление в ближайшем времени на российском рынке нового средства базовой терапии К18 в линии Исеак позволит более целенаправленно воздействовать на сальные железы, уменьшая их размер и фрункциональную активность. В состав средства вошли сбалансированные компоненты на основе экстракта солодки, яблочной кислоты, комплекса гиалуроновой 


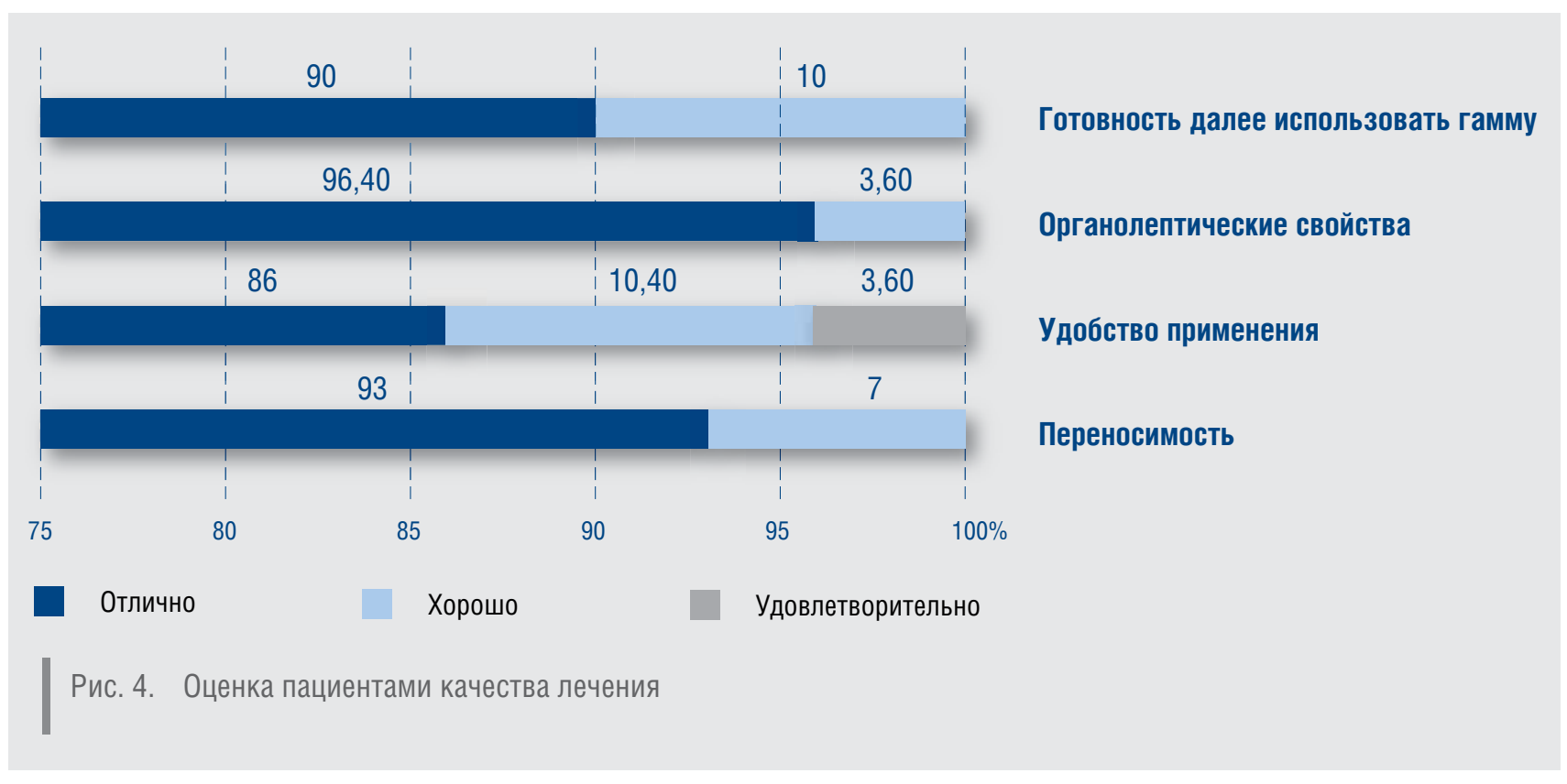

кислоты и аргинина, оказывающие пролонгированное, кератолитическое, себоредуцирующее действие, сопоставимое с эфффектами топических ретиноидов. Сочетание средств базовой терапии Исеак K18 и
Al-эмульсии на фоне адекватного ухода позволит всесторонне воздействовать на все основные механизмы развития акне и существенно повысить результативность терапии. I

\section{Литература}

1. Akne i rozatsea. Pod red. N.N. Potekaeva. M: Binom 2007; 215. [Акне и розацеа. Под ред. Н.Н. Потекаева. М: Бином 2007; 215.]

2. Kubanova A.A., Samsonov V.A., Zabnenkova O.V. Sovremennye osobennosti patogeneza i terapii akne. Vestn dermatol i venerol 2003; 1: 9-16. [Кубанова А.А., Самсонов В.А., Забненкова О.В. Современные особенности патогенеза и терапии акне. Вестн дерматол и венерол 2003; 1: 9-16.]

3. Josipovitch G., Tang M., Dawn F.G. et al. Study of psychological stress, sebum production and acne vulgaris in adolescencents. Acta Dermato-Venerologica 2007; 87: 135-139.

4. Esterbauer H., Gebicki J., Puhl H. The role of lipid peroxidation and antioxidants in oxidative modification of LDF. Free Radic Biol Med 1992; 13: 341—390.
5. Plewig G. Acne and rosacea / G. Plewig, A.M. Kligman. Berlin 1993; 555-673.

6. ONeil D.A., Porter E.M., Elewaut D. et al. Expression and regulation of the human beta-defensins $\mathrm{hBD}-1$ and hBD-2 in intestinal epithelium. J Immunol 1999; 163: 6718-24.

7. Schwandner R., Dziarski R., Wesche H., Rothe M., Kirschning C.J.' Peptidoglycan- and lipoteichoic acidinduced cell activation is mediated by toll-like receptor 2. J Biol Chem 1999; 274: 17406-9.

8. Skripkin Yu.K. i dr. Kozhnye i venericheskie bolezni: rukovodstvo dlya vrachey. M: Meditsina 1995; 2 : 17-19. [Скрипкин Ю.К. и др. Кожные и венерические болезни: руководство для врачей. М: Медицина 1995; 2: 17-19.]
9. Zimina I.V., Lopukhin Yu.M., Arion V.Ya. Kozha kak immunnyy organ: kletochnye elementy i tsitokiny. Immunologiya 1994; 1: 8-13. [Зимина И.В., Лопухин Ю.М., Арион В.Я. Кожа как иммунный орган: клеточные элементы и цитокины. Иммунология 1994; 1: 8-13.]

10. Strcinlein J.W. Skin - associated limfoid tissue (SALT): original and function. J Invest Dermatol 1983; 80: $12-16$

11. Yutskovskaya Ya.A., Mel'nikova E.V., Metlyaeva N.B. Otsenka sostoyaniya psikhoemotsional'noy sfery u bol'nykh akne. Vestn dermatol i venerol 2005; 3 : 48-49. ЮЮцковская Я.А., Мельникова Е.В., Метляева Н.Б. Оценка состояния психоэмоциональной ссферы у больных акне. Вестн дерматол и венерол 2005; 3: 48-49.]

об авторах:

М.М. Тлиш — к.М.Н., зав. кафедрой дерматовенерологии ГБОУ ВПО «КубГМУ» Минздрава Росси, Краснодар

О.А. Катханова - д.м.н., профессор кафедрры дерматовенерологии ГБОУ ВПО «КубГМУ» Минздрава России, Краснодар

Т.Г. Кузнецова — К.М.Н., ассистент кафедры ГБОУ ВПО «КубГМУ» Минздрава России, Краснодар

Ж.Ю. Наатыж - к.м.Н., ассистент кафедры ГБОУ ВПО «КубГМУ» Минздрава России, Краснодар 